\title{
Efeito da calagem e da adubação fosfatada no crescimento inicial e na nutrição das plantas de Khaya ivorensis
}

\author{
Effect of liming and phosphate fertilization on initial growth and nutrition \\ of Khaya ivorensis plants
}

\author{
Clovis Orlando da Ros ${ }^{1 *}$, Geovane Sestari ${ }^{2}$, Cabrieli Jaeger ${ }^{2}$, \\ Emerson Henrique Oliveira ${ }^{2}$, Maitê Luana Weber ${ }^{2}$, Rodrigo Ferreira Silva ${ }^{1}$ e \\ Marcela Torchelsen ${ }^{1}$
}

\begin{abstract}
Resumo
O mogno africano (Khaya ivorensis A. Chev.) é mais uma espécie florestal que vem se destacando em cultivos comerciais no Brasil. No entanto, são escassas as informações sobre a necessidade de correção da acidez do solo e da nutrição das plantas. O objetivo deste estudo foi avaliar a efeito da calagem e da adubação fosfatada nos atributos químicos do solo, no crescimento inicial e na nutrição das plantas. $O$ delineamento experimental foi inteiramente casualizado, com seis repetições, no arranjo fatorial $2 \times 5$. Os tratamentos foram dois níveis de calagem (sem e com) e cinco doses de fósforo $\left(0,10,20,30\right.$ e $40 \mathrm{mg} \mathrm{dm}^{-3} \mathrm{de} P$ ). As mudas, com $16,5 \mathrm{~cm}$ de altura, foram plantadas em vasos de $6,0 \mathrm{~L}$, preenchidos com solo seco ao ar e peneirado em malha de 4,0 mm. Em intervalos de 60 dias, foi avaliada a altura e o diâmetro do colo das plantas do mogno africano. Aos 240 dias do plantio, foi quantificado os atributos químicos do solo, a massa seca e as concentrações de nutrientes das folhas, caule e raízes. A calagem em solo com saturação de bases de $38,5 \%$ não aumentou o crescimento das plantas, mas contribuiu para a redução da acidez, aumento da concentração de $\mathrm{Ca}$ e $\mathrm{Mg}$ no solo e nas folhas. A adubação fosfatada aumentou a disponibilidade de $\mathrm{P}$ no solo e contribuiu para o maior crescimento das plantas de mogno africano.
\end{abstract}

Palavras-chave: mogno africano; altura, massa seca; nutrientes; fertilização.

\begin{abstract}
The african mahogany (Khaya ivorensis A. Chev.) is another forest species that has been standing out in commercial crops in Brazil. However, there is little information on the need to correct soil acidity and plant nutrition. The objective of this study was to evaluate the interference of liming and phosphate fertilization on soil chemical attributes, initial growth and plant nutrition. The experimental design was completely randomized, with six replications, in the $2 \times 5$ factorial arrangement. The treatments were two levels of liming (without and with) and five doses of phosphorus $\left(0,10,20,30\right.$ and $40 \mathrm{mg} \mathrm{dm}^{-3}$ of P). Plant seedlings (16.5 m height) were planted in $6.0 \mathrm{~L}$ pots, filled with air dry soil and sieved in a $4.0 \mathrm{~mm}$ mesh. After 240 days of planting, soil chemical attributes, dry mass and nutrient concentrations of leaves, stems and roots were quantified. Soil liming with basal saturation of $38.5 \%$ did not increase plant growth, but contributed to the reduction of acidity, increase of $\mathrm{Ca}$ and $\mathrm{Mg}$ concentration in soil and leaves. Phosphate fertilization increased $\mathrm{P}$ availability in the soil and contributed to the higher growth of african mahogany plants.
\end{abstract}

Key words: african mahogany; height; dry mass; nutrients, fertilization.

\section{INTRODUÇÃO}

O mogno africano (Khaya ivorensis A. Chev.), da Família Meliaceae, originária da África Ocidental, é uma das principais madeiras nobres introduzidas no Brasil devido a sua boa adaptação às condições de clima e solo do território brasileiro (PINHEIRO et al., 2011). É uma espécie pioneira de crescimento rápido, de grande porte e de madeira de alto valor comercial (FRANÇA et al., 2015). Os cultivos comerciais podem ser realizados em grande parte do território nacional (ROSA, 2014), porém, a disponibilidade de informações sobre calagem e adubação é limitada em comparação aos cultivos de Pinus e Eucalyptus (CORCIOLI et al., 2016; RIBEIRO et al., 2017).

\footnotetext{
1. Departamento de Ciências Agronômicas e Ambientais, Universidade Federal de Santa Maria - UFSM. Santa Maria / RS, Brasil.

2. Departamento de Engenharia Florestal, Universidade Federal de Santa Maria - UFSM. Santa Maria / RS, Brasil.

* Autor Correspondente: clovisdaros@gmail.com
}

Sci. For., Piracicaba, v. 47, n. 123, p. 430-439, set. 2019

DOI: doi.org/10.18671/scifor.v47n123.05 
A calagem dever ser a primeira prática de manejo da fertilidade do solo em áreas de cultivos de plantas, com o objetivo de adequar o ambiente de crescimento das plantas com a correção da acidez do solo e minimizar o efeito tóxico do Al trocável às plantas (ZOZ et al., 2009). No entanto, a adaptação às condições de acidez do solo é diferente entre as espécies florestais, com resposta variável com a elevação da saturação por bases (BRAGA et al., 2015; FREITAS et al., 2017; OLIVEIRA, 2015; OLIVEIRA et al., 2018; VARGAS; MARQUES, 2017).

O fósforo (P) é considerado um dos nutrientes que mais limita o crescimento das espécies florestais, pois o nutriente possui papel fundamental nas plantas, compondo parte das estruturas dos compostos de armazenamento e transporte de energia, como o trifosfato de adenosina (YAMADA; ABDALA, 2004). A deficiência nutricional de P acarreta menor número de folhas e de raízes laterais e redução na produção de biomassa da parte aérea (GAZOLA et al., 2015).

A alta interação do ânion fosfato com os colóides do solo aumenta a retenção do nutriente e, consequentemente, reduz a disponibilidade para as plantas (MOTTA et al., 2002). Neste caso, a correção da acidez do solo pode aumentar a disponibilidade de P para as plantas, principalmente em solos com predominância de argilominerais 1:1 e com alta concentração de óxidos de ferro e alumínio, característica de solos argilosos em estágio avançado de intemperização (SOUZA et al., 2010; ZOZ et al, 2009)

A maior disponibilidade de P ocorre com a elevação do pH na faixa entre 5,5 e 6,5, que é a ideal para o desenvolvimento da maioria das culturas. Como a maioria das espécies florestais são mais tolerantes ao nível de acidez do solo do que as culturas de grãos, forrageiras, frutíferas e olerícolas, a recomendação de calagem é com o objetivo de fornecer Ca e Mg do que corrigir o pH do solo (SBCS, 2016). Nesta condição, o fator calagem pode ser menos preponderante quando não se analisa o potencial que esta prática apresenta em aumentar a disponibilidade de P para as plantas, em solos ácidos e com baixa fertilidade (SILVA et al., 2011).

Neste contexto, o objetivo deste trabalho foi avaliar a disponibilidade de P no solo, crescimento inicial e a nutrição de plantas de mogno africano em função da calagem associada à adubação fosfatada.

\section{MATERIAL E MÉTODOS}

O estudo foi realizado durante os meses de setembro de 2016 a maio de 2017, no Viveiro Florestal da Universidade Federal de Santa Maria, campus de Frederico Westphalen, RS, localizado na latitude $27^{\circ} 23^{\prime} 46^{\prime \prime}$ Sul, longitude $53^{\circ} 25^{\prime} 32^{\prime \prime}$ Oeste e altitude de $490 \mathrm{~m}$. O clima da região é subtropical úmido com verão quente, tipo Cfa, com máximas iguais ou superiores a $22^{\circ} \mathrm{C}$, mínimas entre -3 a $18^{\circ} \mathrm{C} \mathrm{e}$ precipitação média anual entre 1.900 e 2.200 mm (ALVARES et al., 2013).

O solo utilizado no experimento, caracterizado como Latossolo Vermelho aluminoférrico típico (EMBRAPA, 2014), foi coletado na camada de 0-20 cm em uma área de vegetação permanente de gramíneas. Os atributos químicos foram quantificados conforme metodologias descrita em Silva, Abreu e Pérez. (2009): 1,3 mg dm${ }^{-3}$ de Pe $157 \mathrm{mg} \mathrm{dm}^{-3}$ de K, extraídos por Mehlich-1; 0,8 $\mathrm{cmol}_{c} \mathrm{dm}^{-3}$ de Al trocável, 3,1 $\mathrm{cmol}_{c} \mathrm{dm}^{-3}$ de Ca e 1,7 $\mathrm{cmol}_{c} \mathrm{dm}^{-3}$ de $\mathrm{Mg}$ extraídos com solução de $\mathrm{KCl}$ 1,0 mol L-1; $18,8 \mathrm{mg} \mathrm{dm}^{-3}$ de Cu e 2,9 $\mathrm{mg} \mathrm{dm}^{-3}$ de Zn extraídos com $\mathrm{HCl} \mathrm{0,1} \mathrm{mol} \mathrm{L}^{-1} ; 13,5 \mathrm{cmol}_{\mathrm{c}} \mathrm{dm}^{-3}$ de CTC potencial; $38,5 \%$ de saturação por bases; $13,3 \%$ de saturação por Al; $37,2 \mathrm{~g} \mathrm{~kg}^{-1}$ de matéria orgânica; pH em água de 5,1 e índice SMP de 5,5. Os resultados da análise granulométrica foram de 716,7 $\mathrm{g} \mathrm{kg}^{-1}$ de argila, 185,7 $\mathrm{g} \mathrm{kg}^{-1}$ de silte e 97,7 $\mathrm{g} \mathrm{kg}^{-1}$ de areia (EMBRAPA, 2011).

O delineamento experimental foi inteiramente casualizado, com seis repetições, no esquema fatorial 2 x 5: dois níveis de calagem (sem e com) e cinco doses de $\mathrm{P}\left(0,10,20,30\right.$ e $\left.40 \mathrm{mg} \mathrm{dm}^{-3}\right)$. As quantidades de P foram equivalentes, respectivamente, a 0, 50, 100, 150 e $200 \mathrm{~kg} \mathrm{ha}^{-1} \mathrm{de}_{2} \mathrm{O}_{5^{\prime}}$ aplicadas uniformemente na camada de $0-20 \mathrm{~cm}$. A fonte de $\mathrm{P}$ utilizada foi o superfosfato triplo, com $46 \%$ de $\mathrm{P}_{2} \mathrm{O}_{5}$ e $10 \%$ de Ca.

A dose de calcário aplicada (3,6 t ha ${ }^{-1}$ com PRNT de 100\%) foi calculada pelo método da saturação por bases para elevar a saturação 65\%. Foi utilizado o calcário dolomítico (PRNT=60,11\%) com $26,2 \%$ de $\mathrm{CaO}$ e $13,5 \%$ de $\mathrm{MgO}(\mathrm{PN}=80,37 \%)$ e granulometria de 100, 85 e 52\% de partículas menores que 2,00; 0,84 e 0,30 mm, respectivamente. O calcário foi aplicado no plantio das mudas com o objetivo de simular a prática de uso do corretivo quando é realizada a implantação das mudas a campo. 
Da Ros et al. - Efeito da calagem e da adubação fosfatada no crescimento

inicial e na nutrição das plantas de Khaya ivorensis

Juntamente com o calcário e com a adubação fosfatada foi aplicado $50 \mathrm{mg} \mathrm{dm}^{-3} \mathrm{de} \mathrm{N} \mathrm{e} 65 \mathrm{mg} \mathrm{dm}^{-3}$ de $\mathrm{K}$, equivalente a $100 \mathrm{~kg} \mathrm{ha}^{-1}$ de $\mathrm{N}$ e $150 \mathrm{~kg} \mathrm{ha}^{-1}$ de $\mathrm{K}_{2} \mathrm{O}$. As fontes comerciais utilizadas foram a ureia e o cloreto de potássio, respectivamente. Os fertilizantes foram moídos e, junto com o calcário, misturados ao solo com base no volume de solo de cada tratamento e homogeneizado com auxílio de uma betoneira. Em cobertura (186 dias do plantio) foram aplicados $175 \mathrm{~mL}$ por unidade experimental da solução contendo $1,65 \mathrm{~g}$ de ureia $\mathrm{L}^{-1}$ e 1,25 $\mathrm{g}$ de $\mathrm{KCl} \mathrm{L}^{-1}$, equivalente as doses de $45 \mathrm{~kg} \mathrm{ha}^{-1}$ de $\mathrm{N}$ e de $\mathrm{K}_{2} \mathrm{O}$.

A unidade experimental foi composta por um vaso de 6,0 L, preenchido com solo seco ao ar e peneirado em malha de 4,0 mm. As mudas de mogno africano, provenientes de sementes adquiridas no Instituto Brasileiro de Florestas, com altura média de $16,5 \mathrm{~cm}$, foram plantadas nos vasos em $16 / 09 / 2016$. Após o transplantio das mudas, foi realizada irrigação para atingir $80 \%$ da capacidade de campo e, posteriormente, receberam quatro irrigações diárias, equivalente a 7,8 $\mathrm{mm} \mathrm{dia}^{-1}$.

As avaliações de crescimento das plantas em altura e em diâmetro do colo foram realizadas aos 60, 120, 180 e 240 dias após o transplantio das mudas. A altura da parte aérea foi medida com régua graduada do colo da planta até o ápice caulinar e o diâmetro do colo foi medido com paquímetro digital, com precisão de $0,01 \mathrm{~mm}$. A avaliação da massa seca foi realizada no final do experimento (240 dias), após a separação das folhas, caule e raízes e secagem em estufa a $65^{\circ} \mathrm{C}$, até massa constante. As raízes foram separadas do solo com auxílio de peneira de 2,0 mm e jatos de água.

Após a secagem, as amostras da parte aérea e raízes foram pesadas em balança de precisão $(0,01 \mathrm{~g})$, moídas e quantificadas as concentrações de $\mathrm{N}, \mathrm{P}, \mathrm{K}$, Ca e $\mathrm{Mg}$ por meio de extração com $\mathrm{H}_{2} \mathrm{SO}_{4}$ concentrado, usando 0,2 g de material triturado em moinho tipo Willey, com peneira de malha de $0,5 \mathrm{~mm}$. A determinação do $\mathrm{N}$ total foi realizada pelo método do microdestilador e titulação com $\mathrm{H}_{2} \mathrm{SO}_{4^{\prime}}$ o P por espectrofotometria com azul de molibdênio, o K por fotometria de chamas e o Ca e Mg por espectrometria de absorção atômica, conforme metodologias para análise química de tecido vegetal descrita em Miyazawa et al. (2009).

A avaliação dos atributos químicos do solo foi realizada em amostras coletadas durante o processo de separação das raízes (uma amostra por unidade experimental), após secagem em estufa a $40^{\circ} \mathrm{C}$ e moídas em moinho tipo martelo com peneira de malha de 2,0 mm, conforme Silva, Abreu e Pérez (2009). O P e K foram extraídos com solução 0,05 mol L-1 de ácido clorídrico e 0,0125 mol L-1 de ácido sulfúrico (extrator Mehlich-1) e a determinação por colorimetria e fotometria de chama, respectivamente; o Ca e $\mathrm{Mg}$ com solução 1,0 $\mathrm{mol} \mathrm{L}^{-1}$ de $\mathrm{KCl}$ e determinação por espectrometria de absorção atômica; o Al trocável com solução 1,0 mol L-1 de $\mathrm{KCl}$ e determinação por titulometria com hidróxido de sódio e o pH na suspensão solo e água na relação 1:1 por potenciometria. A acidez potencial $(\mathrm{H}+\mathrm{Al})$ foi estimada a partir da determinação do $\mathrm{pH}$ índice SMP pela equação: $\mathrm{H}+\mathrm{Al}$ $\left(\mathrm{cmol}_{\mathrm{c}} \mathrm{dm}^{-3}\right)=\left(\mathrm{e}^{10.665-1.1483 \mathrm{SMP}}\right) / 10$; a saturação por bases e a saturação por $\mathrm{Al}$ foram calculadas com base na equações descritas pela SBCS (2016).

Os resultados foram submetidos à análise de variância e quando apresentaram interação significativa, desdobraram-se os efeitos do fator qualitativo (calcário) dentro de cada nível do fator quantitativo (doses de $\mathrm{P}$ ), sendo as médias do fator qualitativo comparadas pelo teste de $\mathrm{F}$ $(\mathrm{p}<0,05)$ e as do fator quantitativo pela análise de regressão polinomial $(\mathrm{p}<0,05)$. Quando não houve interação significativa, o efeito simples de cada fator de variação foi analisado separadamente, sendo o qualitativo pelo teste F e o quantitativo pela análise de regressão polinomial. A escolha da equação de regressão polinomial foi com base no maior grau significativo do teste $\mathrm{F}$, considerando o coeficiente de determinação maior que $60 \%$, Os dados foram analisados no programa estatístico computacional Sisvar (FERREIRA, 2011).

\section{RESULTADOS E DISCUSSÃO}

\section{Atributos químicos do solo após o cultivo do mogno africano}

Os atributos da acidez do solo relacionados ao pH e saturação por alumínio aos 240 dias do transplantio das mudas de mogno africano apresentaram interação significativa $(p<0,05)$ entre os fatores calcário e doses de P (Figura 1).

$\mathrm{O}$ pH do solo aumentou com as doses de $\mathrm{P}$ no tratamento que recebeu calcário e diminuiu no solo sem calagem (Figura 1A). A relação inversa do efeito do fertilizante fosfatado nas condições de solo, 

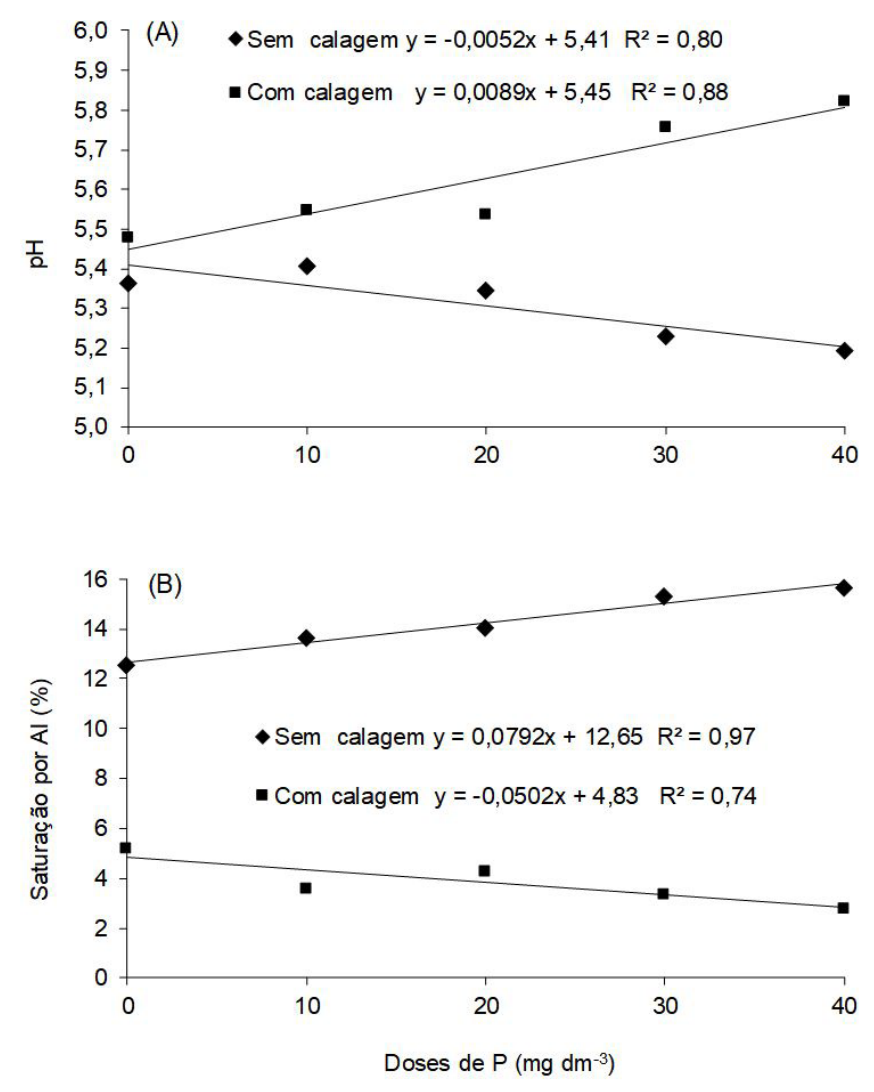

Figura 1. Efeito das doses de $\mathrm{P}$, na forma de superfosfato triplo, no $\mathrm{pH}(\mathrm{A})$ e na saturação por $\mathrm{Al}$ (B) em solo sem e com calagem aos 240 dias do cultivo das mudas do mogno africano.

Figure 1. Effect of $\mathrm{P}$ doses on $\mathrm{pH}(\mathrm{A})$ and saturation by $\mathrm{Al}(\mathrm{B})$ in soil without and with liming at 240 days of seedling cultivation of african mahogany.

com e sem calagem, pode ser explicada pela interação do efeito ácido do superfosfato triplo com o efeito alcalinizante do calcário. Provavelmente, com a calagem a acidificação ao redor dos grânulos do fosfato foi reduzida pela ação das oxidrilas proveniente da reação do calcário, não se refletindo na redução do pH do solo com a adição do fertilizante fosfatado. Nesta condição, a adição de fosfato pode também resultar na formação de compostos de $\mathrm{Al}$ de baixa solubilidade, que contribui para a sua inativação no solo, reduzindo a sua toxidez para as plantas (ERNANI et al., 2001; NOLLA; ANGHINONI, 2006).

Observa-se que a contribuição da calagem na redução da acidez do solo foi maior em comparação ao uso da adubação fosfatada, indicando maior importância da calagem na correção da acidez do solo. Na dose máxima de $\mathrm{P}$, a saturação por Al diminuiu de 15,8\% no tratamento sem calagem para 2,8\% no tratamento com calagem (Figura 1B). Na média das doses de $\mathrm{P}$, a saturação por bases aumentou, respectivamente, de 48,8 para $68,8 \%$ e a acidez potencial diminuiu de 6,0 para $4,4 \mathrm{cmol}_{\mathrm{c}} \mathrm{dm}^{-3}$ (Tabela 1), indicando eficácia do calcário na redução da acidez do solo.

Os atributos químicos do solo relacionados à disponibilidade de $\mathrm{P}, \mathrm{K}$, Ca e Mg não apresentaram interação significativa $(\mathrm{p}<0,05)$ entre calcário e doses de $\mathrm{P}$, indicando a mesma tendência de resposta às doses de $\mathrm{P}$ nos tratamentos com e sem calagem (Tabela 1). Com os dados médios dos tratamentos com e sem calagem, a análise de regressão indicou ausência de resposta às doses de P para os teores de $\mathrm{K}$ e Mg e resposta linear para P e Ca no solo.

O teor de P disponível no solo foi de $0,7 \mathrm{mg} \mathrm{dm}^{-3}$ no tratamento sem P e de $2,3 \mathrm{~g} \mathrm{dm}^{-3}$ na dose máxima do nutriente utilizado ( $\left.40 \mathrm{mg} \mathrm{dm}^{-3}\right)$, representando um incremento de $0,04 \mathrm{mg} \mathrm{dm}^{-3}$ para cada unidade de P aplicado no solo (Tabela 1). O teor de fósforo disponível no solo elevou de "muito baixo" ( $\left.\leq 1,5 \mathrm{mg} \mathrm{dm}^{-3}\right)$ para "baixo" $\left(1,6-3,0 \mathrm{mg} \mathrm{dm}^{-3}\right)$, conforme a classe de interpretação para as espécies florestais da SBCS (2016). Observa-se que o incremento não foi suficiente para elevar o teor de P no solo ao limite crítico $\left(4,5 \mathrm{mg} \mathrm{dm}^{-3}\right)$, independente da aplicação ou não de calagem.

$\mathrm{O}$ baixo incremento de $\mathrm{P}$ disponível com a adubação fosfatada está relacionado à alta energia de adsorção do ânion fosfato às cargas positivas dos colóides. Esta retenção do nutriente é intensificada 
Da Ros et al. - Efeito da calagem e da adubação fosfatada no crescimento

inicial e na nutrição das plantas de Khaya ivorensis

Tabela 1. Efeito da calagem e das doses de $P$ na saturação por bases $(V)$, na acidez potencial $(A l+H)$ e na disponibilidade de nutrientes no solo aos 240 dias do transplantio das mudas de mogno africano.

Table 1. Effect of liming and $P$ rates on basal saturation $(V)$, potential acidity $(A I+H)$ and soil nutrient availability at 240 days of transplanting of african mahogany seedlings.

\begin{tabular}{|c|c|c|c|c|}
\hline \multirow[b]{2}{*}{ Parâmetros avaliados } & \multicolumn{2}{|c|}{ Efeito da calagem ${ }^{(1)}$} & \multicolumn{2}{|c|}{ Efeito das doses de $\mathbf{P}^{(1)}$} \\
\hline & Sem & Com & $\begin{array}{l}\text { Equação de } \\
\text { regressão }\end{array}$ & $\mathbf{R}^{2}$ \\
\hline V $(\%)$ & $38,8^{*}$ & 68,8 & $\hat{y}=53,1+0,084 x^{*}$ & 0,93 \\
\hline $\mathrm{Al}+\mathrm{H}\left(\mathrm{cmol}_{\mathrm{c}} \mathrm{dm}^{-3}\right)$ & $6,0^{*}$ & 4,4 & $\hat{y}=\bar{y}=5,0^{\text {ns }}$ & \\
\hline$P\left(\mathrm{mg} \mathrm{dm}^{-3}\right)$ & $1,4^{\mathrm{ns}}$ & 1,6 & $\hat{y}=0,7+0,039 x^{*}$ & 0,95 \\
\hline $\mathrm{K}\left(\mathrm{mg} \mathrm{dm}^{-3}\right)$ & $121,4^{\mathrm{ns}}$ & 119,0 & $\hat{y}=\bar{y}=120,2^{\text {ns }}$ & \\
\hline $\mathrm{Ca}\left(\mathrm{cmol}_{\mathrm{c}} \mathrm{dm}^{-3}\right)$ & $3,5^{*}$ & 5,3 & $\hat{y}=3,8+0,029 x^{*}$ & 0,71 \\
\hline $\mathrm{Mg}\left(\mathrm{cmol}_{\mathrm{c}} \mathrm{dm}^{-3}\right)$ & $1,9^{*}$ & 3,7 & $\hat{y}=\bar{y}=2,8^{n s}$ & \\
\hline
\end{tabular}

(')Interação não significativa ( $\mathrm{<}<0,05)$ : média das doses de $\mathrm{P}$ para o efeito calagem e média dos tratamentos com e sem calagem para o efeito doses de $P .{ }^{n s} e^{*}$ não significativo e significativo para o teste $F$ (efeito calagem) e para a análise de regressão (efeito doses de $P$ ), a $5 \%$ de probabilidade de erro $(p<0,05)$.

em solos argilosos e com alta concentração de óxidos de ferro e alumínio, característica de solos em estágio avançado de intemperização (MOTTA et al., 2002), como os Latossolos. Além disso, a moagem dos grânulos do fertilizante fosfatado com o objetivo de aumentar a uniformização do fertilizante na unidade experimental e a incorporação da dose equivalente à camada de $0-20 \mathrm{~cm}$, provavelmente, aumentou a adsorção aos colóides do solo, pois a forma de aplicação da adubação fosfatada é outro fator que afeta a disponibilidade de fósforo no solo (DA ROS et al., 2017).

Em um estudo com a incorporação de $80 \mathrm{mg} \mathrm{kg}^{-1}$ de P em um Latossolo Bruno Alumínico típico, com $550 \mathrm{~g} \mathrm{~kg}^{-1}$ de argila e baixo teor do nutriente, Ernani et al. (2001) não encontraram aumento de P disponível no solo. Os autores ressaltam que em condições de alta capacidade de retenção de $\mathrm{P}$, a aplicação localizada dos fosfatos é mais eficiente que a sua incorporação no solo. Como a recomendação de adubação para as espécies florestais indica aplicar na cova ou no sulco de plantio (SBCS, 2016), o teor de P disponível no solo deve aumentar nestes locais, em detrimento do teor do nutriente entre as plantas e as linhas de plantio. Se o objetivo é atender a demanda do nutriente nos estágios iniciais de crescimento, a localização da adubação fosfatada será mais eficiente.

Com relação à calagem, não houve aumento do teor de $\mathrm{P}$ disponível no solo em comparação ao tratamento sem calagem (Tabela 1). O aumento do $\mathrm{pH}$ do solo proporcionado pela calagem, de 5,1 para 5,6 (Figura 1A), provavelmente não foi suficiente para reduzir os sítios de adsorção do ânion fosfatado nos argilominerais 1:1 e óxidos, diminuindo dessa forma quimissorção do nutriente no solo (MOTTA et al., 2002; ZOZ et al., 2009).

Os teores de Ca disponíveis (trocáveis) no solo aumentaram com a aplicação de calcário e com as doses de $\mathrm{P}$ (Tabela 1). O aumento está relacionado à presença do nutriente no calcário e no fertilizante fosfatado. Com a calagem o aumento de Ca foi de $1,8 \mathrm{cmol}_{c} \mathrm{dm}^{-3}$, maior em comparação à adubação fosfatada $\left(1,2 \mathrm{cmol}_{\mathrm{c}} \mathrm{dm}^{-3}\right)$. No caso do $\mathrm{Mg}$, o aumento foi somente com a calagem, devido a sua presença no corretivo. Já no K, não houve aumento no solo devido à ausência do nutriente na composição do calcário e do fertilizante.

\section{Crescimento inicial das plantas de mogno africano}

Os parâmetros morfológicos de crescimento das plantas em altura e em diâmetro do colo, nas quatro avaliações realizadas durante 240 dias após o transplantio das mudas, e a massa seca da parte aérea e radicular, avaliada no final deste período, não indicaram interação significativa $(\mathrm{p}<0,05)$ entre o fator calcário e doses de P. Estes resultados indicam que as doses de P apresentaram a mesma tendência de resposta para as condições de solo com e sem calagem (Tabela 2).

A aplicação de calcário não alterou a altura, o diâmetro do colo e a massa seca da parte aérea e radicular das plantas de mogno africano (Tabela 2). A resposta à calagem na maioria das culturas ocorre quando a acidez do solo está associada à presença de Al trocável acima do limite crítico de crescimento das plantas, acrescido de baixa disponibilidade de nutrientes, principalmente de Ca e Mg que são adicionados com o uso de calcários dolomíticos (SBCS, 2016).

O limite crítico de saturação das cargas efetivas do solo por Al trocável é de 15\%, relatado como não prejudicial para o crescimento da maioria das plantas (OLMOS; CAMARGO, 1976). 
Tabela 2. Altura, diâmetro do colo e massa seca (MS) da parte aérea (folhas + caule) e das raízes das plantas de mogno africano em função das doses de P adicionadas ao solo com e sem calagem.

Table 2. Height, stem diameter and dry mass of the aerial part (leaves + stem) and of the roots of the african mahogany plants as a function of the $\mathrm{P}$ doses added to the soil with and without liming.

\begin{tabular}{|c|c|c|c|c|}
\hline \multirow{2}{*}{$\begin{array}{l}\text { Dias após o } \\
\text { transplantio }\end{array}$} & \multicolumn{2}{|c|}{ Efeito da calagem ${ }^{(1)}$} & \multicolumn{2}{|c|}{ Efeito das doses de $\mathrm{P}^{(1)}$} \\
\hline & Sem & Com & Equação de regressão & $\mathbf{R}^{2}$ \\
\hline \multicolumn{5}{|c|}{ 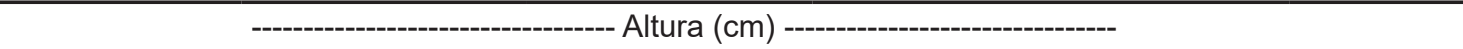 } \\
\hline 60 & $23,7^{\mathrm{ns}}$ & 24,1 & $\hat{y}=22,3+0,083 x^{*}$ & 0,91 \\
\hline 120 & $35,3^{\text {ns }}$ & 36,3 & $\hat{y}=32,5+0,165 x^{*}$ & 0,86 \\
\hline 180 & $48,4^{\text {ns }}$ & 50,4 & $\hat{y}=45,0+0,217 x^{*}$ & 0,84 \\
\hline \multirow[t]{2}{*}{240} & $60,1^{\mathrm{ns}}$ & 62,1 & $\hat{y}=57,3+0,202 x^{*}$ & 0,74 \\
\hline & \multicolumn{4}{|c|}{-------------------------- Diâmetro do colo (cm) --------------------- } \\
\hline 60 & $7,9^{\text {ns }}$ & 8,0 & $\hat{y}=\bar{y}=8,0^{\text {ns }}$ & \\
\hline 120 & $11,0^{\text {ns }}$ & 11,2 & $\hat{y}=10,2+0,045 x^{*}$ & 0,94 \\
\hline 180 & $13,2^{\text {ns }}$ & 13,6 & $\hat{y}=12,9+0,024 x^{*}$ & 0,65 \\
\hline 240 & $16,4^{\mathrm{ns}}$ & 16,5 & $\hat{y}=15,3+0,060 x$ * & 0,82 \\
\hline \multirow[t]{2}{*}{240} & \multicolumn{4}{|c|}{ 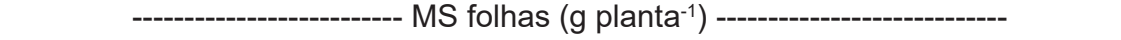 } \\
\hline & \multicolumn{4}{|c|}{ 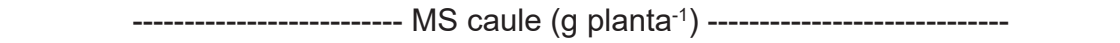 } \\
\hline \multirow[t]{2}{*}{240} & $17,7^{\mathrm{ns}}$ & 16,9 & $\hat{y}=13,1+0,209 x^{*}$ & 0,90 \\
\hline & \multicolumn{4}{|c|}{ 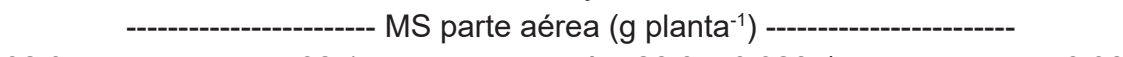 } \\
\hline 240 & $32,9^{\text {ns }}$ & 32,1 & $\hat{y}=26,0+0,326 x^{*}$ & 0,96 \\
\hline 240 & $23,4^{\mathrm{ns}}$ & 23,4 & $\hat{y}=18,3+0,252 x^{*}$ & 0,90 \\
\hline
\end{tabular}

(I)Interação não significativa $(\mathrm{p}<0,05)$ : média das doses de $\mathrm{P}$ para o efeito calagem e média dos tratamentos com e sem calagem para o efeito doses de $P .{ }^{n s} e^{*}$ não significativo e significativo para o teste $F$ (efeito calagem) e para a análise de regressão (efeito doses de $P$ ), a $5 \%$ de probabilidade de erro $(p<0,05)$.

No entanto, a tolerância das plantas a presença do Al trocável no solo é variável, pois está relacionada a mecanismos de redução da toxidez do elemento, que são controlados por fatores fisiológicos e genéticos (MIGUEL et al., 2010).

As espécies florestais, em comparação às culturas anuais, são tolerantes ao Al trocável do solo e, consequentemente, têm menores respostas à correção da acidez do solo (SBCS, 2016). No caso do mogno africano utilizado no presente estudo, a ausência de resposta à calagem nos parâmetros de crescimento pode ser explicada pela baixa saturação por Al no solo na implantação do experimento $(13,3 \%)$, associado aos adequados teores de Ca e Mg no solo. No entanto, maiores estudos em diferentes tipos de solos e com variação nos níveis de acidez são necessários para delimitar a faixa adequada de crescimento desta espécie, pois estudos com espécies florestais apontam resposta ao uso de calagem com valores de saturação por bases até 64\% (BRAGA et al., 2015; SILVA et al., 2011; SOUZA et al., 2010; VARGAS; MARQUES, 2017).

A análise de regressão apresentou resposta crescente às doses de P para a altura, diâmetro do colo e massa seca das folhas, caule e raízes das plantas do mogno africano, exceção da avalição realizada aos 60 dias para o diâmetro do colo (Tabela 2). O aumento do crescimento das plantas ocorre quando o teor de P no solo encontra-se abaixo do teor crítico (SBCS, 2016). No caso do solo do presente estudo com teor de $1,3 \mathrm{mg} \mathrm{dm}^{-3}$ de $\mathrm{P}$ (muito baixo) no transplantio das mudas, inferior ao limite crítico $\left(4,5 \mathrm{mg} \mathrm{dm}^{-3}\right)$, a resposta foi esperada nos parâmetros morfológicos analisados.

$\mathrm{O}$ incremento com a dose máxima de $\mathrm{P}$ aplicada no solo, aos 240 dias após o transplantio das mudas, foi de 14,$1 ; 15,7 ; 50,1$ e 55,1\% para a altura, diâmetro do colo, massa seca da parte aérea e raízes, respectivamente (Tabela 2 ). Como houve resposta linear até a dose máxima de $\mathrm{P}$ aplicado no solo, não foi possível delimitar a dose de máxima eficiência técnica, provavelmente devido à moagem e incorporação do fertilizante fosfatado em área total que diminui a disponibilidade do nutriente no solo.

A taxa de crescimento das espécies florestais é outro fator que influencia na eficiência de utilização do P. Em um estudo com quatro espécies florestais, em um Latossolo Vermelho Amarelo, com baixo teor de P, Fontes et al. (2013) destacaram maior resposta as doses de P na produção de massa seca no cedro-australiano (Toona ciliata), seguido do cedro rosa (Cedrela fissilis), mogno brasileiro (Swietenia macrophylla) e sabiá (Mimosa caesalpiniaefolia). 
Da Ros et al. - Efeito da calagem e da adubação fosfatada no crescimento

inicial e na nutrição das plantas de Khaya ivorensis

O mogno africano é considerado uma espécie de crescimento rápido (FRANÇA et al., 2015), portanto, tende a responder com maior intensidade à adubação em comparação as espécies de crescimento mais lento. Oliveira (2015) encontraram resposta na altura de plantas de mogno africano (Khaya senegalensis A. Juss) até $125 \mathrm{mg} \mathrm{dm}^{-3}$ de $\mathrm{P}$ em um experimento conduzido em vasos de $7,0 \mathrm{dm}^{-3}$ por 180 dias do plantio. Vasconcelos et al. (2017), em um estudo com aplicação de P nas laterais de cada lado das linhas de plantio (50 cm do ponto de colocação da muda), encontraram incremento no crescimento das plantas em altura e diâmetro à altura do peito do Khaya senegalensis aos dois anos de idade até a dose máxima de $\mathrm{P}\left(120 \mathrm{~kg} \mathrm{ha}^{-1}\right.$ de $\left.\mathrm{P}_{2} \mathrm{O}_{5}\right)$.

Estes estudos divergem dos obtidos por Alves Junior et al. (2017), na região do Cerrado brasileiro, que destacam que o mogno africano é uma espécie adaptada a solos com baixos teores de nutrientes. Apesar da adaptação a solos pouco férteis, Gonçalves et al. (2013) destacam a importância da disponibilização adequada de nutrientes no solo na implantação de plantios florestais para potencializar a produtividade de madeira, independente da espécie florestal.

\section{Concentração de nutrientes nas plantas de mogno africano}

As concentrações de N, P, K e Ca e Mg na parte aérea e nas raízes das plantas de mogno africano, aos 240 dias após o transplantio das mudas, não apresentaram interação significativa $(p<0,05)$ entre os fatores calcário e doses de $\mathrm{P}$, indicando que a resposta as doses de $\mathrm{P}$ na concentração de cada nutriente na planta foi a mesma sem e com calcário (Tabela 3).

A adubação fosfatada aplicada no solo não alterou a concentração de $\mathrm{N}$ na parte aérea e radicular, reduziu a concentração de $\mathrm{K}$ nas folhas e caule, aumentou a concentração de $\mathrm{Mg}$ nas folhas e de Ca no caule (Tabela 3). No caso do P, as concentrações nas folhas, no caule e nas raízes das plantas foram afetadas de forma diferente em função das doses de P. Nas folhas, a equação de regressão foi quadrática, com maior concentração $\left(2,0 \mathrm{~g} \mathrm{~kg}^{-1}\right)$ na dose de $23,8 \mathrm{mg} \mathrm{kg}^{-1}$ do nutriente, e no caule e nas raízes foi linear, com aumento até a dose máxima do elemento aplicado no solo.

A influência da adubação fosfatada na concentração de K não é padrão nos estudos que relacionam estes dois nutrientes, pois há relatos que mostram diminuição (CORCIOLI et al., 2016), aumento

Tabela 3. Efeito da calagem e das doses de $P$ na concentração de $N, P, K, C a$ e $M g$ nas folhas, caule e raízes das plantas de mogno africano aos 240 dias do transplantio das mudas.

Table 3. Effect of liming and $P$ rates on $N, P, K, C a$ and $M g$ concentration on leaf, stem and roots of african mahogany plants at 240 days of seedling transplant.

\begin{tabular}{|c|c|c|c|c|}
\hline \multirow{2}{*}{$\begin{array}{l}\text { Parâmetros } \\
\text { avaliados }\end{array}$} & \multicolumn{2}{|c|}{ Efeito da calagem ${ }^{(1)}$} & \multicolumn{2}{|c|}{ Efeito das doses de $\mathrm{P}^{(1)}$} \\
\hline & Sem & Com & Equação de regressão & $\mathbf{R}^{2}$ \\
\hline & \multicolumn{4}{|c|}{ 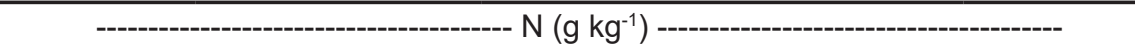 } \\
\hline Folhas & $12,64^{\mathrm{ns}}$ & 12,48 & $\hat{y}=\bar{y}=12,56^{\mathrm{ns}}$ & \\
\hline Caule & $3,56^{\text {ns }}$ & 2,85 & $\hat{y}=\bar{y}=3,21^{\mathrm{ns}}$ & \\
\hline Raízes & $4,34^{\text {ns }}$ & 4,77 & $\hat{y}=\bar{y}=4,55^{\mathrm{ns}}$ & \\
\hline & \multicolumn{4}{|c|}{ 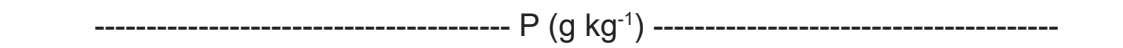 } \\
\hline Folhas & $1,67^{\text {ns }}$ & 2,01 & $\hat{y}=1,56+0,038 x-0,0008 x^{2 *}$ & 0,88 \\
\hline Caule & $1,18^{\text {ns }}$ & 1,33 & $\hat{y}=1,07+0,0095 x^{*}$ & 0,80 \\
\hline Raízes & $0,98^{\text {ns }}$ & 1,01 & $\hat{y}=0,88+0,0057 x^{*}$ & 0,63 \\
\hline Folhas & \multicolumn{4}{|c|}{ - } \\
\hline Caule & $7,33^{\text {ns }}$ & 7,57 & $\hat{y}=9,32-0,0362 x^{*}$ & 0,61 \\
\hline Raízes & $8,24^{\text {ns }}$ & 8,95 & $\hat{y}=\bar{y}=8,60^{\text {ns }}$ & \\
\hline Folhas & \multicolumn{4}{|c|}{$9,08^{*} \quad 13,81 \quad \hat{y}=\bar{y}=11,44^{n s}$} \\
\hline Caule & $3,19^{*}$ & 3,83 & $\hat{y}=3,17+0,0172 x^{*}$ & \multirow[t]{2}{*}{0,84} \\
\hline Raízes & $2,34^{\text {ns }}$ & 2,81 & $\hat{y}=\bar{y}=2,58^{\text {ns }}$ & \\
\hline & \multicolumn{4}{|c|}{--------------------------------------- $\mathrm{Mg}\left(\mathrm{g} \mathrm{kg}^{-1}\right)$---------------------------------- } \\
\hline Folhas & $2,54^{*}$ & 3,01 & $\hat{y}=2,59+0,0091 x^{*}$ & 0,77 \\
\hline Caule & $1,43^{\text {ns }}$ & 1,65 & $\hat{y}=\bar{y}=1,54^{\text {ns }}$ & \\
\hline Raízes & $1,72^{\text {ns }}$ & 1,93 & $\hat{y}=\bar{y}=1,82^{n s}$ & \\
\hline
\end{tabular}

(')Interação não significativa ( $\mathrm{<}<0,05)$ : média das doses de $\mathrm{P}$ para o efeito calagem e média dos tratamentos com e sem calagem para o efeito doses de $\mathrm{P}$. ${ }^{\mathrm{ns}} \mathrm{e}$ * não significativo e significativo para o teste $\mathrm{F}$ (efeito calagem) e para a análise de regressão (efeito doses de $\mathrm{P}$ ), a $5 \%$ de probabilidade de erro $(p<0,05)$. 
(NAKAGAWA; ROSOLEM, 2005) e não alteração (BOYHAN et al., 2007), não sendo possível estabelecer um padrão definido sobre o efeito da adubação fosfatada no estado nutricional de K nas plantas (ZAMBROSI, 2011).

O aumento da concentração de $\mathrm{Mg}$ nas folhas com as doses de P se deve ao sinergismo entre os dois nutrientes, pois uma das principais funções do Mg nas plantas é a sua participação como ativador enzimático na maioria das enzimas fosforilativas, tanto na incorporação como na transferência do P inorgânico. Quanto mais P absorvido pelas plantas, maior será a necessidade de $\mathrm{Mg}$ para formar as pontes entre ATP e/ou ADP e a molécula de enzima (SILVA; TREVIZAM, 2015).

$\mathrm{O}$ aumento da concentração de $\mathrm{P}$ na parte aérea e radicular provavelmente está relacionado à sua maior disponibilidade no solo com a adubação fosfatada. Além de aumentar a concentração na planta, a adubação fosfatada contribuiu para o maior crescimento das plantas, justificando o seu uso em solos com teores limitantes do nutriente no solo. No entanto, devido ao crescimento das plantas até a dose máxima de P aplicado no solo, não foi possível de estimar a dose de máxima eficiência técnica.

A aplicação de calcário não alterou as concentrações de N, P e K na parte aérea e nas raízes das plantas (Tabela 3). Houve alteração para as concentrações de Mg nas folhas e de Ca nas folhas e no caule. O aumento do $\mathrm{pH}$ do solo com a calagem provavelmente não foi suficiente em reduzir os sítios de adsorção de P no solo e, consequentemente, aumentar a disponibilidade do nutriente que está presente no solo e daquele proveniente da adubação fosfatada (ZOZ et al., 2009). No caso do Ca e $\mathrm{Mg}$, o aumento da concentração dos nutrientes nas folhas se deve ao aumento da disponibilidade no solo devido a calagem.

As concentrações de Ca e Mg nas folhas aumentaram com a calagem de 9,08 a 13,81 e de 2,54 a 2,95 $\mathrm{g} \mathrm{kg}^{1}$, respectivamente (Tabela 3). Em um estudo com mogno africano, Corcioli et al. (2016) encontraram, aos 220 dias do transplantio de mudas, com suplementação adequada de macro e micronutrientes, valores próximos ao presente estudo. Como os parâmetros morfológicos, de altura, diâmetro do colo e massa seca não foram alterados pela calagem, indica que não houve limitação de Ca e Mg para o crescimento das plantas. Portanto, a calagem não foi necessária nas condições de solo em que foi conduzido o experimento com o objetivo de fornecer maior quantidade destes nutrientes para as plantas. Além disso, a correção da acidez do solo também não foi necessária para o cultivo do mogno africano no presente estudo com saturação de bases de 38,5\%, indicando que pode incluir esta espécie no mesmo critério das demais espécies florestais relacionadas pela SBCS (2016), que delimita valor menor que $40 \%$ de saturação por bases para a tomada de decisão de aplicação de calcário.

\section{CONCLUSÕES}

- A calagem não é necessária para o cultivo de mogno africano em Latossolos com saturação de bases de 38,5\%, pois não contribui para o aumento do crescimento das plantas, disponibilidade de P no solo e da nutrição do elemento nas plantas.

- A adubação fosfatada é necessária para o aumento do crescimento do mogno africano em solos com baixa disponibilidade de P no solo, independente da calagem.

\section{REFERÊNCIAS BIBLIOGRÁFICAS}

ALVARES, C. A.; STAPE, J. L.; SENTELHAS, P. C.; GONÇALVES, J. L. M.; SPAROVEK, G. Köppen's climate classification map for Brazil. Meteorologische Zeitschrift, Stuttgart, v. 22, n. 6, p. 711-728, 2013.

ALVES JÚNIOR, J.; BARBOSA, L. H. A.; ROSA, F. O.; CASAROLI, D.; EVANGELISTA, A. W. P.; VELLAME, L. M. African mahogany submitted to drip irrigation and fertilization. Revista Árvore, Viçosa, v. 41, n. 1, e410112, 2017.

BOYHAN, G. E.; TORRANCE, R. L.; HILL, C. R. Effects of nitrogen, phosphorus, and potassium rates and fertilizer sources on yield and leaf nutrient status of short-day onions. HortScience, Alexandria, v. 42, n. 3, p. 653-660, 2007.

BRAGA, M. M.; NETO, A. E. F;; OLIVEIRA, A. H. Influência da saturação por bases na qualidade e crescimento de mudas de cedro-australiano (Toona ciliata M. Roem var. australis). Ciência Florestal, Santa Maria, v. 25, n. 1, p. 49-58, 2015. 
Da Ros et al. - Efeito da calagem e da adubação fosfatada no crescimento

inicial e na nutrição das plantas de Khaya ivorensis

CORCIOLI, G.; BORGES, J. D.; JESUS, R. P. Deficiência de macro e micronutrientes em mudas maduras de Khaya ivorensis estudadas em viveiro. Cerne, Lavras, v. 22, n. 1, p. 121-128, 2016.

DA ROS, C. O.; MATSUOKA, M.; SILVA, R. F. S.; SILVA, V, R. Interference from the vertical variation of soil phosphorus and from water stress on growth in maize, the soybean and sunflower. Revista Ciência Agronômica, Fortaleza, v. 48, n. 3, p. 419-427, 2017.

EMBRAPA - EMPRESA BRASILEIRA DE PESQUISA AGROPECUÁRIA. Manual de métodos de análises de solo. 2 ed. Rio de Janeiro: Embrapa Solos, 2011, 230 p.

EMBRAPA - EMPRESA BRASILEIRA DE PESQUISA AGROPECUÁRIA. Sistema brasileiro de classificação de solos. 4. ed. Rio de Janeiro, Embrapa Solos, 2014. 376 p.

ERNANI, P. R.; STECKLING, C.; BAYER, C. Características químicas de solo e rendimento de massa seca de milho em função do método de aplicação de fosfatos, em dois níveis de acidez. Revista Brasileira de Ciência do Solo, Viçosa, v. 25, n. 4, p. 939-946, 2001.

FERREIRA, D. F. Sisvar: A computer statistical analysis system. Ciência e Agrotecnologia, Lavras, v. 35, n. 6, p.1039-1042, 2011.

FONTES, A. G.; GAMA-RODRIGUES, A. C.; GAMA-RODRIGUES, E. F. Eficiência nutricional de espécies arbóreas em função da fertilização fosfatada. Pesquisa Florestal Brasileira, Colombo, v. 33, n. 73, p. 9-17, 2013.

FRANÇA, T. S. F. A.; ARANTES, M. D. C.; PAES, J. B.; VIDAURRE, G. B.; OLIVEIRA, J. T. S.; BARAÚNA, E. E, P. Características anatômicas e propriedades físico-mecânicas das madeiras de duas espécies de mogno africano. Cerne, Lavras. v. 21, n. 4, p. 633-640, 2015.

FREITAS, E. C. S.; PAIVA, H. N.; LEITE, H. G.; OLIVEIRA NETO, S. N. Crescimento e qualidade de mudas de Cassia grandis Linnaeus f. em resposta à adubação fosfatada e calagem. Ciência Florestal, Santa Maria, v. 27, n. 2, p. 509-519, 2017.

GAZOLA, R, N.; BUZETTI, S.; TEIXEIRA FILHO, M, C.; DINALLI, R. P.; MORAES, M. L. T.; CELESTRINO, T. S.; SILVA, P. H. M.; DUPAS, E. Doses de N, P e K na cultura do eucalipto em solo originalmente sob Cerrado. Semina: Ciências Agrárias, Londrina, v. 36, n. 3, suplemento 1, p. 1895-1912, 2015.

GONÇALVES, E. O.; PAIVA, H. N.; NEVES, J. C. L.; GOMES, J. M. Nutrição de mudas de Mimosa caesalpiniaefolia Benth. sob diferentes doses de N, P, K, Ca e Mg. Ciência Florestal, Santa Maria, v. 23, n. 2, p. 273-286, 2013.

MIGUEL, P. S. B.; GOMES, F. T.; ROCHA, W. S. D.; CARVALHO, C. A.; OLIVEIRA, A. V. Efeitos tóxicos do alumínio no crescimento das plantas: mecanismos de tolerância, sintomas, efeitos fisiológicos, bioquímicos e controles genéticos. CES Revista, Juiz de Fora, v. 24, p. 11-30, 2010.

MIYAZAWA, M.; PAVAN, M. A.; CARMO, C. A. F. S.; MELO, W. J. Análise química de tecido vegetal. In: SILVA, F. C. (Ed). Manual de análises químicas de solos, plantas e fertilizantes. 2. ed. Brasília, DF: Embrapa Informações Tecnológica. 2009. p. 191-233.

MOTTA, P. E. F.; CURI, N.; SIQUEIRA, J. O.; VAN RAIJ, B.; FURTINI NETO, A. E.; LIMA, J. M. Adsorção e formas de fósforo em Latossolos: influência da mineralogia e histórico de uso. Revista Brasileira de Ciência do Solo, Viçosa, v. 26, n. 2, p. 349 - 359, 2002.

NAKAGAWA, J.; ROSOLEM, C. A. Teores de nutrientes na folha e nos grãos de aveia-preta em função da adubação com fósforo e potássio. Bragantia, Campinas, v. 64, n. 3, p. 441-445, 2005.

NOLLA, A.; ANGHINONI, I. Atividade e especiação química na solução afetadas pela adição de fósforo em Latossolo sob plantio direto em diferentes condições de acidez. Revista Brasileira de Ciência do Solo, Viçosa, v. 30 n. 6, p. 955-963, 2006.

OLIVEIRA, C. S. Efeito do fósforo no desenvolvimento inicial de plantas de mogno-africano. 2015. 18 p. Dissertação (Mestrado em Produção Vegetal) - Universidade Estadual de Goiás, Ipameri, 2015.

OLIVEIRA, R.; SOUZA, N. F.; PIETROSKI, M.; FERBONINK, G. F.; CAIONE, G. Mudas de Tectona grandis produzidas em diferentes níveis de saturação por bases do solo. Revista de Agricultura Neotropical, Cassilândia, v. 5, n. 2, p. 31-38, 2018. 
OLMOS, J. I. L.; CAMARGO, M. N. Ocorrência de alumínio tóxico nos solos do Brasil, sua caracterização e distribuição. Ciência Cultura, Campinas, v. 28, n. 2, p. 171 - 180, 1976.

PINHEIRO, A. L.; COUTO, L.; PINHEIRO, D. T.; BRUNETTA, J. M. F. C. Ecologia, silvicultura e tecnologia de utilização dos mognos-africanos (Khaya spp.). Viçosa: Sociedade Brasileira de Agrossilvicultura, 2011. 102 p.

RIBEIRO, A.; FILHO, A. C. F.; SCOLFORO, J. R. S. O cultivo do mogno africano (Khaya spp.) e o crescimento da atividade no Brasil. Floresta e Ambiente, Seropédica, v. 24, p. 1-11, 2017.

ROSA, F. O. Zoneamento edafoclimático e respostas do mogno africano às condições do cerrado. 2014. 85 p. Dissertação (Mestrado em Agronomia) - Escola de Agronomia e Engenharia de Alimentos, Universidade Federal de Goiás, Goiânia, 2014.

SBCS - SOCIEDADE BRASILEIRA DE CIÊNCIA DO SOLO. Manual de calagem e adubação para os Estados do Rio Grande do Sul e de Santa Catarina. 11 ed. Frederico Westphalen: Núcleo Regional Sul, Comissão de Química e Fertilidade do Solo, 2016. 376 p.

SILVA, M. L. S.; TREVIZAM, A. R. Interações iônicas e seus efeitos na nutrição das plantas. Informações Agronômicas, Peachtree Corners, n. 149, p. 10-16, 2015.

SILVA, F. C.; ABREU, M. F.; PÉREZ, D. V. Métodos de análises químicas para avaliação da fertilidade do solo. In: SILVA, F. C. (Ed.). Manual de análises químicas de solos, plantas e fertilizantes. 2. ed. Brasília, DF: Embrapa Informações Tecnológica. 2009. p. 107-189.

SILVA, T. A. F.; TUCCI, C. A. F.; SANTOS, J. Z. L.; BATISTA, I, M. P.; MIRANDA, J. F.; SOUZA, M. M. Calagem e adubação fosfatada para a produção de mudas de Swietenia macrophylla. Floresta, Curitiba, v. 41, n. 3, p. 459-470, 2011.

SOUZA, C. A. S.; TUCCI, C. A. F.; SILVA, J. F.; RIBEIRO, W. O. Exigências nutricionais e crescimento de plantas de mogno (Swietenia macrophylla King.). Acta Amazonica, Manaus, v. 40, n. 3, p. 515-522, 2010.

VARGAS, G.; MARQUES, R. Crescimento e nutrição de angico e canafístula sob calagem e gessagem. Floresta e Ambiente, Seropédica, v. 24, p. 1-10, 2017.

VASCONCELOS, R. T.; VALERI, S. V.; CRUZ, M. C. P.; BARBOSA, J. C.; BARRETTO, V. C. Fertilização fosfatada na implantação de Khaya senegalensis A. Juss. Scientia Forestalis, Piracicaba, v. 45, n. 116, 2017.

YAMADA, T.; ABDALLA, S, R. S. Fósforo na agricultura brasileira. 3 ed. Piracicaba: Potafos, 2004.726 p.

ZAMBROSI, F. C. B. Adubação com fósforo em cana-soca e sua interação com magnésio. Bragantia, Campinas, v. 71, n. 3, p. $400-405,2011$.

ZOZ, T.; LANA, M. C.; STEINER, F.; FRANDOLOSO, J. F.; FEY, R. Influência do pH do solo e de fertilizantes fosfatados sobre a adsorção de fósforo em Latossolo vermelho. Synergismus Scyentifica UTFPR, Pato Branco, v. 4, n. 1, p. 1-3, 2009.

Recebido em: 02/03/2018

Aceito em: 31/10/2018 